\title{
Characterization of heme binding to recombinant $\alpha_{1}$-microglobulin
}

\author{
Elena Karnaukhova ${ }^{1 *}$, Sigurbjörg Rutardottir ${ }^{2}$, Mohsen Rajabi $^{3}$, Lena Wester Rosenlöf ${ }^{2}$, \\ Abdu I. Alayash ${ }^{1}$ and Bo Åkerström ${ }^{2 *}$ \\ Laboratory of Biochemistry and Vascular Biology, Division of Hematology Research and Review, Center for Biologics Evaluation and Research, Food and Drug \\ Administration, Silver Spring, MD, USA \\ ${ }^{2}$ Division of Infection Medicine, Department of Clinical Sciences in Lund, Lund University, Lund, Sweden \\ ${ }^{3}$ Division of Therapeutic Proteins, Office of Biotechnology Products, Office of Pharmaceutical Science, Center for Drug Evaluation and Research, Food and Drug \\ Administration, Silver Spring, MD, USA
}

Edited by:

Sruti Shiva, University of

Pittsburgh, USA

Reviewed by:

Angela Wilks, University of

Maryland, USA

Rudolf Lucas, Medical College of

Georgia, USA

*Correspondence:

Elena Karnaukhova, Center for

Biologics Evaluation and Research,

Food and Drug Administration, Silver

Spring, MD 20993, USA

e-mail:elena.karnaukhova@

fda.hhs.gov;

Bo Åkerström, Division of Infection

Medicine, Department of Clinical

Sciences in Lund, Lund University,

BMC B14, 22184 Lund, Sweden

e-mail:bo.akerstrom@med.lu.se
Background: Alpha-1-microglobulin (A1M), a small lipocalin protein found in plasma and tissues, has been identified as a heme ${ }^{1}$ and radical scavenger that may participate in the mitigation of toxicities caused by degradation of hemoglobin. The objective of this work was to investigate heme interactions with $\mathrm{A} 1 \mathrm{M}$ in vitro using various analytical techniques and to optimize analytical methodology suitable for rapid evaluation of the ligand binding properties of recombinant $\mathrm{A} 1 \mathrm{M}$ versions.

Methods: To examine heme binding properties of $\mathrm{A} 1 \mathrm{M}$ we utilized UV/Vis absorption spectroscopy, visible circular dichroism (CD), catalase-like activity, migration shift electrophoresis, and surface plasmon resonance (SPR), which was specifically developed for the assessment of His-tagged A1M.

Results: The results of this study confirm that $A 1 M$ is a heme binding protein that can accommodate heme at more than one binding site and/or in coordination with different amino acid residues depending upon heme concentration and ligand-to-protein molar ratio. UVNis titration of A1M with heme revealed an unusually large bathochromic shift, up to $38 \mathrm{~nm}$, observed for heme binding to a primary binding site. UVNis spectroscopy, visible $\mathrm{CD}$ and catalase-like activity suggested that heme is accommodated inside His-tagged ( $\operatorname{tg} \mathrm{A} 1 \mathrm{M})$ and tagless $\mathrm{A} 1 \mathrm{M}(\mathrm{nt} \mathrm{A} 1 \mathrm{M})$ in a rather similar fashion although the His-tag is very likely involved into coordination with iron of the heme molecule. SPR data indicated kinetic rate constants and equilibrium binding constants with $K_{D}$ values in a $\mu \mathrm{M}$ range.

Conclusions: This study provided experimental evidence of the $\mathrm{A} 1 \mathrm{M}$ heme binding properties by aid of different techniques and suggested an analytical methodology for a rapid evaluation of ligand-binding properties of recombinant $\mathrm{A} 1 \mathrm{M}$ versions, also suitable for other His-tagged proteins.

Keywords: alpha-1-microglobulin, heme binding, surface plasmon resonance, circular dichroism

\section{INTRODUCTION}

Heme (iron-protoporphyrin IX) is a prosthetic group of hemoglobin $(\mathrm{Hb})$, myoglobin and many other hemoproteins that perform a wide range of biological functions such as oxygen delivery, iron storage, electron transfer, and substrate oxidation (Smith et al., 2010). However, once released from $\mathrm{Hb}$ and other hemoproteins, heme is capable of generating reactive oxygen species that can oxidatively damage lipids and proteins, leading to oxidative stress and cell and tissue damage (Jeney et al., 2002; Buehler et al., 2011). Heme toxicity is seen in several

Abbreviations: A1M, $\alpha_{1}$-microglobulin; CD, circular dichroism; CE, Cotton Effect; DMSO, dimethyl sulfoxide; HA, human albumin; His8, histidine octapeptide; HPX, hemopexin; L/P, ligand-to-protein (molar) ratio; ntAlM, non-tagged alpha-1-microglobulin; PBS, phosphate buffer saline; SPR, surface plasmon resonance; $\operatorname{tg} A 1 M$, His-tagged alpha-1-microglobulin; RU, response units. pathological conditions including hemolytic disorders such as malaria, $\beta$-thalassemia and sickle-cell disease (Vinchi et al., 2013; Dutra and Bozza, 2014). Recently, heme was shown to bind specifically to the Toll-like Receptor (TLR4) leading to endothelial cell activation and vaso-occlusion in murine sickle cell disease (Belcher et al., 2014).

$\mathrm{Hb}$, the most abundant heme-containing protein in the circulation, is the major source of free heme due to catabolism of extracellular $\mathrm{Hb}$ in hemolytic disorders. Exogenous sources of free heme include red blood cell (RBC) preparations during storage (Buehler et al., 2011), heme-based therapeutics (such as Panhematin, hemin for injection, and heme arginate) that are

\footnotetext{
${ }^{1}$ The term "heme" is used in this article to denote both the ferrous and ferric
} forms. 
used for the treatment of porphyrias (Tenhunen and Mustajoki, 1998; Siegert and Holt, 2008), and Hb-based blood substitutes (Alayash, 2014). In the circulation, the free heme redox toxicity is mitigated by several innate defense mechanisms, including heme sequestration by plasmatic major heme scavengers hemopexin, albumin, and some other proteins (Ascenzi et al., 2005; Buehler et al., 2011). A1M, also known as protein HC, has emerged among anti-oxidative defense mechanisms as a tissue housekeeping protein which is capable of capturing heme and free radicals (Allhorn et al., 2002; Åkerström et al., 2007; Olsson et al., 2012; Åkerström and Gram, 2014), as well as reducing oxidative lesions (Allhorn et al., 2005; Olsson et al., 2008; Rutardottir et al., 2013). This small heterogeneously charged glycoprotein ( $\sim 26 \mathrm{kDa}$ ) belongs to the lipocalin protein family, a group of small extracellular proteins that are known for a great diversity of their primary sequence, but share a well-conserved tertiary structure ( kerström et al., 2000; Flower, 2000). The lipocalins share a common fold, a $\beta$-barrel consisting of eight antiparallel $\beta$-strands with a closed bottom, an open end and a hydrophobic pocket which can carry small lipophilic ligands (Ganfornina et al., 2006). Whereas precise physiological functions of A1M and many other lipocalins are not defined yet, these proteins are known for their ligand-binding properties and thus, seem to play an important role in binding, storage and transport of small lipophilic molecules (Breustedt et al., 2006). A1M was shown to bind heme in different species (Allhorn et al., 2002; Larsson et al., 2004). Because of its radical and heme binding properties and antioxidant potential, $\mathrm{A} 1 \mathrm{M}$ is being considered for several therapeutic applications ( $\AA$ kerström and Gram, 2014), and recombinant Histagged A1M has been successfully employed for in vivo treatment of preeclampsia in a sheep model (Wester-Rosenlöf et al., 2014) and $\mathrm{Hb}$-induced glomerular dysfunction in rats (Sverrisson et al., 2014).

A previous study suggested that each A1M-molecule binds two heme-groups (Siebel et al., 2012). The aim of this study was to characterize the interactions of recombinant A1M with heme using various analytical techniques. Our analytical methodology included (a) UV/Vis monitoring of the A1M titration by heme, (b) evaluation of a possible involvement of the recombinant A1M His-tag into a coordination with iron of the heme molecule, (c) visible circular dichroism (CD) to characterize heme/A1M interactions by aid of protein-induced chirality (induced CD), and (d) development of surface plasmon resonance (SPR) analysis suitable for the immobilization of recombinant A1M by the His-tag per se to study the interactions with heme and/or other ligands without removal of the tag.

\section{MATERIALS AND METHODS \\ MATERIALS}

Hemin, dimethyl sulfoxide (DMSO), L-His, imidazole, and essentially fatty acid free human serum albumin (HA) were purchased from Sigma Chemical Co. (St. Louis, MO). Recombinant human A1M with an N-terminal His8-tag (tgA1M) was expressed and purified in E.coli as described (Kwasek et al., 2007), with the addition of ion-exchange chromatography and size exclusion purification steps performed as follows. The protein solution was applied to a column of DEAE-Sephadex A-50 (GE
Healthcare, Uppsala, Sweden) equilibrated with the starting buffer $(20 \mathrm{mM}$ Tris- $\mathrm{HCl}, \mathrm{pH} 8.0)$. A1M was eluted at a flow rate of $1 \mathrm{ml} / \mathrm{min}$ using a linear $\mathrm{pH}$ gradient consisting of $250 \mathrm{ml}$ starting buffer and $250 \mathrm{ml}$ elution buffer $(20 \mathrm{mM}$ Tris- $\mathrm{HCl}$, $0.15 \mathrm{M} \mathrm{NaCl}, \mathrm{pH} 8.0$ ). Size-exclusion chromatography was run on a Superose 12 column obtained from GE Healthcare using Äkta purifier 10 system (GE Healtcare) run at a flow-rate of $1 \mathrm{ml} / \mathrm{min}$. Notag A1M (ntA1M) was a obtained from A1M Pharma (Lund, Sweden). Research grade CM5 sensor chips, NTA sensor chip, 1-ethyl-3-(3-dimethyl-aminopropyl)-carbodiimide hydrochloride (EDC), N-hydroxysuccinimide, ethanolamine$\mathrm{HCl}$, HBS-P buffer (0.01 M HEPES, pH 7.4, 0.15 M NaCl, $0.005 \%$ surfactant P20), Phosphate buffer saline, 10X (PBS) $(0.1 \mathrm{M}$ phosphate buffer with $27 \mathrm{mM} \mathrm{KCl}$ and $1.37 \mathrm{M} \mathrm{NaCl}$, $\mathrm{pH} 7.4$ ), acetate buffer ( $\mathrm{pH} 5.0), \mathrm{NaOH}(50 \mathrm{mM})$, and deionized water were from GE Healthcare (Piscataway, NJ). Anti-His mouse IgG1 monoclonal antibodies were purchased from $R \& D$ Systems (Minneapolis, MN). Hemopexin (HPX) was from Athens Research Technologies (Athens, GA). Other chemicals were analytical grade from Fisher Scientific (Fair Lawn, NJ).

\section{PREPARATION OF PROTEIN SOLUTIONS}

Protein stock solutions (22 and $45 \mu \mathrm{M}$ ) of A1M, HA, HPX were prepared in $20 \mathrm{mM}$ Tris- $\mathrm{HCl}, 0.15 \mathrm{M} \mathrm{NaCl}, \mathrm{pH} 8.0$ (Tris buffer), aliquoted and stored frozen at $-70^{\circ} \mathrm{C}$ until use. A1M samples in PBS or Tris buffer were prepared by dilution of the concentrated stock solutions prior to use. Concentrations of the reference proteins HA and HPX were determined spectrophotometrically using a molar extinction coefficient of $5.5 \times 10^{4} \mathrm{M}^{-1} \mathrm{~cm}^{-1}$ for HA (Gill and von Hippel, 1989) and $1.1 \times 10^{5} \mathrm{M}^{-1} \mathrm{~cm}^{-1}$ for apo-HPX (Eskew et al., 1999).

\section{PREPARATION OF IMIDAZOLE, L-HIS AND HIS8 SOLUTIONS}

Imidazole and L-His solutions were prepared in Tris buffer at concentrations $100 \mathrm{mM}$ and $50 \mathrm{mM}$, respectively, to provide a large excess over the heme to be added. A His-octapeptide was synthesized at CBER Core facility (Silver Spring, MD) and dissolved to $100 \mathrm{mM}$ in Tris buffer prior to adding of heme aliquots followed by UV/Vis spectral measurements.

\section{PREPARATION OF HEME SOLUTION}

Heme stock solutions (2.4 and $1.2 \mathrm{mM}$ ) were freshly prepared in DMSO for each experiment, purged with argon and stored (protected from light) at $4^{\circ} \mathrm{C}$ during use. The heme concentrations in the stock solutions were determined spectrophotometrically using heme molar extinction coefficient of $170,000 \mathrm{M}^{-1} \mathrm{~cm}^{-1}$ at $\lambda_{\max } 404 \mathrm{~nm}$ (Collier et al., 1979).

\section{UV/VIS MEASUREMENTS}

UV/Vis electronic absorption spectra were measured on Agilent HP8453 UV-visible spectrophotometer (Agilent Technologies Deutschland $\mathrm{GmbH}$, Germany) at $25 \pm 0.2^{\circ} \mathrm{C}$ in a quartz cuvette of $1 \mathrm{~cm}$ pathlength. The measurements were performed in the range of $250-700 \mathrm{~nm}$ for $\mathrm{A} 1 \mathrm{M}$ interactions with heme. UV/Vis differential spectra of the heme/A1M samples were measured using A1M as a blank. 


\section{A1M TITRATION WITH HEME}

Titration of A1M samples with heme was performed using $45 \mu \mathrm{M}$ A1M preparations in Tris buffer. Heme concentration was increased stepwise by addition of $2 \mu \mathrm{L}$ aliquots of $2.1 \mathrm{mM}$ heme stock solution in DMSO to a $1 \mathrm{~mL}$ of $45 \mu \mathrm{M}$ protein solution. UV/Vis and CD recordings were repeated until no significant alterations were observed, before the next heme aliquot was added. During titration the samples were maintained at room temperature, protected from light and periodically flashed by argon. Initial $45 \mu \mathrm{M}$ A1M solutions served as a blank. The total amount of DMSO in the titration samples did not exceed $2 \% \mathrm{v} / \mathrm{v}$. Titration of A1M with heme was carried out until the ligand-to-protein molar ratio $(\mathrm{L} / \mathrm{P})$ was 1.4 . Since signs of turbidity and slight precipitation were observed for the samples with high heme content, only the data up to $\mathrm{L} / \mathrm{P} 1.0$ were included.

\section{MIGRATION SHIFT ELECTROPHORESIS}

Tris buffer with $5 \mu \mathrm{M}$ tgA1M or ntA1M was incubated for $15 \mathrm{~min}$ at room temperature with 50,5,0.5, and $0 \mu \mathrm{M}$ heme. Samples were mixed with equal amounts of sample buffer for native PAGE, $\mathrm{pH}$ 6.8, and subjected to electrophoresis on $12 \%$ Criterion $^{\mathrm{TM}}$ $\mathrm{TGX}^{\mathrm{TM}}$ Precast stainfree gels (Bio-Rad) under non-denaturing and non-reducing conditions. The gel was first imaged by tryptophan fluorescence with a BioRad GelDoc MP Imaging system and then stained with Coomassie Brilliant Blue R-250 (BDH Chemicals, Ltd. Poole, UK).

\section{MEASUREMENTS}

CD measurements were performed using a Jasco J-815 Spectropolarimeter (JASCO Co., Japan) with the temperature maintained at $25 \pm 0.2^{\circ} \mathrm{C}$ by a Peltier thermostat. The spectra were measured at a scan speed of $100 \mathrm{~nm} / \mathrm{min}$, bandwidth of $1.0 \mathrm{~nm}$, and resolution of $0.2 \mathrm{~nm}$ and accumulated in triplicate. All samples containing heme were measured for protein-induced $\mathrm{CD}$ in the near-UV-visible range from 700 to $300 \mathrm{~nm}$ (referred to as visible $\mathrm{CD}$ ). To accumulate the induced $\mathrm{CD}, \mathrm{A} 1 \mathrm{M}$ preparations were used at a concentration $\sim 45 \mu \mathrm{M}$ in Tris buffer, and the measurements of heme/A1M samples were performed in a quartz cuvette with $1 \mathrm{~cm}$ pathlength. Protein alone was used as a blank. Heme/HPX and heme/HA samples were recorded at the same concentration, but in a cuvette with a shorter pathlength $(5 \mathrm{~mm})$ because of the strong induced CD, and then the spectra were normalized. An ellipticity of CD spectra was expressed in millidegrees (mdeg).

\section{SURFACE PLASMON RESONANCE}

SPR experiments were performed using Biacore T200 (GE Healthcare, Piscataway, NJ). About 18,000 response units (RU) anti-His mouse IgG1 monoclonal antibody (R\&D Systems, Minneapolis, MN) were immobilized on CM5 sensors using the amine coupling kit. The tagged protein was captured by injecting $\operatorname{tg} \mathrm{A} 1 \mathrm{M}(10 \mu \mathrm{L} / \mathrm{min})$ for $360 \mathrm{~s}$. Heme samples were prepared prior to injection by serial double dilutions of the initial $100 \mu \mathrm{M}$ heme solution in PBS-P/5\% DMSO to create a range over eight concentrations (from 100 to $0.625 \mu \mathrm{M}$ ). Heme samples prepared at $\mathrm{pH} 7.2$ and $\mathrm{pH} 8$ were injected over captured A1M for $2 \mathrm{~min}$ with a flow $30 \mu \mathrm{L} / \mathrm{min}$ at $25^{\circ} \mathrm{C}$. The dissociation was monitored for $10 \mathrm{~min}$. Data were analyzed using the Biacore T200 evaluation software (GE Healthcare), subtracting the reference surface (immobilized anti-His mouse IgG1 antibody from the captured A1M surface) and buffer control signals from each curve. Data were globally fitted by simultaneous numerical integration to the association and dissociation parts of the interaction, using the heterogeneous ligand kinetic analysis models. Steady-state equilibrium was reached during the association phase, global fitting produced reproducible kinetic parameters. Experimental $R_{\text {maximum response }}\left(R_{\max }\right)$ values obtained by global fitting were comparable to theoretical $R_{\max }$ values calculated from the molecular masses of the interacting proteins and the immobilization level. For the interactions with an equilibrium achieved, $K_{\mathrm{D}}$ was also calculated by an equilibrium analysis.

The T200 BIAevaluation software (version 1.0; Biacore AB, Uppsala, Sweden) offers various reaction models to perform complete kinetic analyses of the sensorgrams, from which the heterogeneous ligand binding model were applied. This model describes an interaction between one analyte and two independent ligands or two binding sites of one ligand. The binding curve obtained is simply the sum of the two independent reactions.

\section{CATALASE-LIKE ACTIVITY ASSAY}

Stability of the Soret band intensity and heme accessibility to hydrogen peroxide in heme/tgA1M and heme/ntA1M samples in comparison with heme alone in Tris buffer were evaluated using the catalase-like activity assay, as described earlier (Karnaukhova et al., 2012) with minor modifications. Briefly, heme/A1M equimolar (L/P 1.0) samples were prepared by adding $21 \mu \mathrm{L}$ of $2.1 \mathrm{mM}$ heme stock solution in DMSO to $1 \mathrm{~mL}$ of $45 \mu \mathrm{M}$ solutions of tgA1M and ntA1M in Tris buffer. The samples were incubated at room temperature for $20 \mathrm{~h}$, protected from light. The complex formation was confirmed by a stable Soret band in the UV/Vis spectra, i.e., $\lambda_{\max }$ at $411 \mathrm{~nm}$ typical for heme/tgA1M (L/P 1.0) and $\lambda_{\max }$ at $389 \mathrm{~nm}$ typical for heme/ntA1M (L/P 1.0), respectively. As a reference, a heme sample in Tris buffer was freshly prepared the same way and used immediately in view of its limited stability in aqueous solutions. The samples were normalized to adjust their Soret bands to approximately the same intensity $(\sim 0.56 \mathrm{AU})$ by dilution with Tris buffer. After addition of a $7 \mu \mathrm{L}$ aliquot of $50 \mathrm{mM} \mathrm{H}_{2} \mathrm{O}_{2}$ solution to $1 \mathrm{~mL}$ of the sample ( $\sim 8$-fold excess over the heme complex content), the absorption spectra were taken at the following time points: $30 \mathrm{~s}, 1,2,4,6,8$, and $10 \mathrm{~min}$.

\section{RESULTS AND DISCUSSION UV/VIS ASSESSMENT}

Due to its hydrophobic nature, free heme possesses a low solubility in aqueous media and has a tendency to aggregate. In organic solvents, such as ethanol or DMSO, heme has much better solubility and exhibits a strong Soret band at $404-405 \mathrm{~nm}$, stable for few days. When an aliquot of a heme stock solution in DMSO was added to a buffer solution, a broad Soret band around $380 \mathrm{~nm}$ with a relatively low intensity was observed which further decreased with time (Figure 1A). However, when a heme aliquot was added to the same buffer (Tris, $\mathrm{pH} \mathrm{8),} \mathrm{containing} \mathrm{A1M,} \mathrm{the}$ 


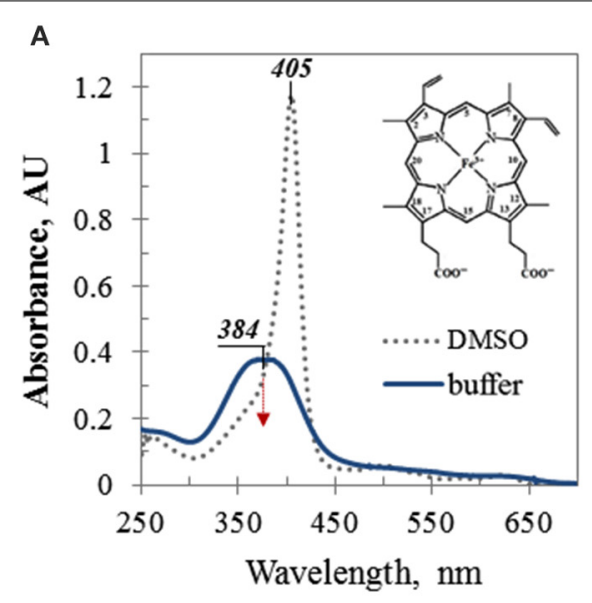

C

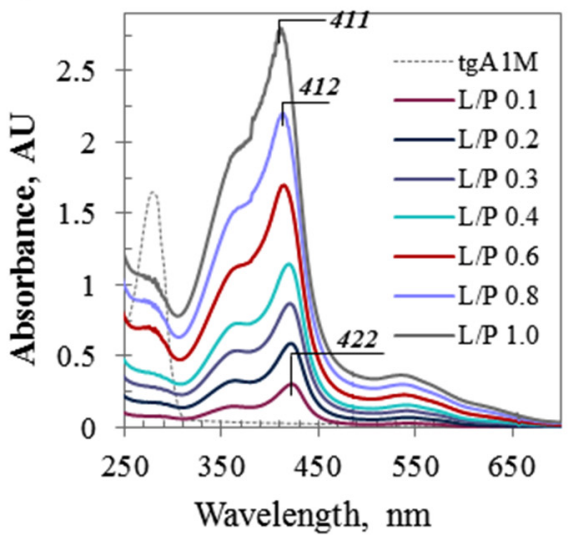

FIGURE 1 | UV/Vis electronic absorbance data. (A) UVNis spectra of heme in Tris buffer and DMSO; the same aliquot of $1.28 \mathrm{mM}$ heme stock solution was added to $1 \mathrm{~mL}$ of buffer or DMSO, respectively; inset shows heme structure; (B) time-course absorbance spectra of $45 \mu \mathrm{M} \mathrm{A1M}$ sample containing 0.1 molar equivalent of heme (L/P 0.1); (C) differential UVNis spectra of the A1M titration by heme (the initial spectrum of $45 \mu \mathrm{M}$ $\mathrm{A} 1 \mathrm{M}$, shown by thin dotted trace, has been subtracted by running the

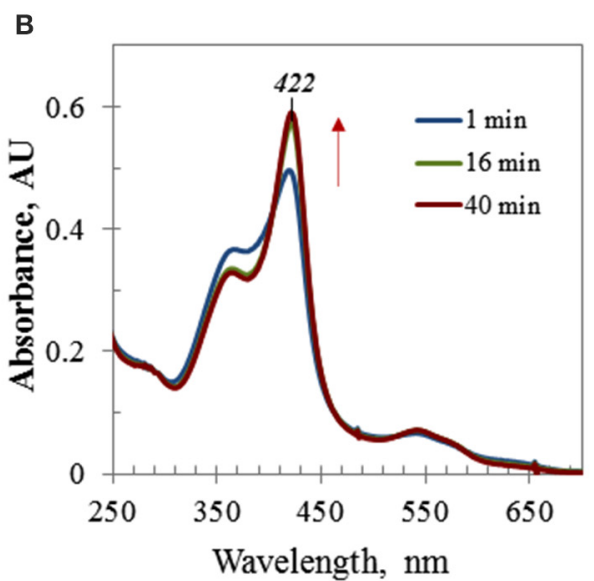

D

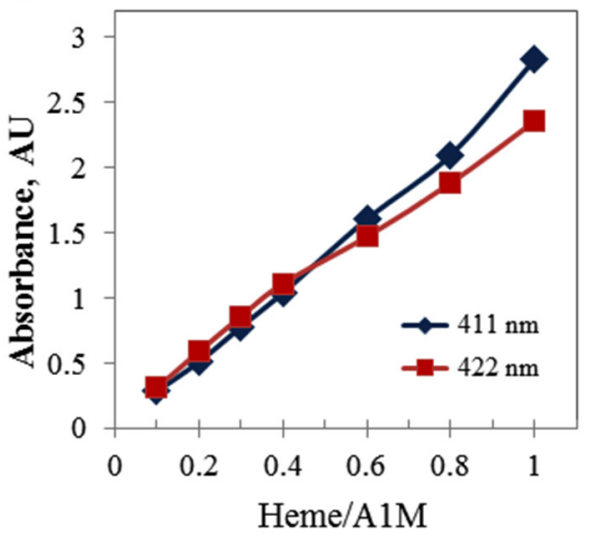

A1M sample as a blank prior to adding heme); the spectra are shown for the time point $40 \mathrm{~min}$; all titration samples were measured in $10 \mathrm{~mm}$ pathlength cuvette, except the last one (L/P 1.0) which spectrum has been recorded in $5 \mathrm{~mm}$ pathlength cuvette and then normalized to $10 \mathrm{~mm}$ path; (D) the absorbance intensities of the Soret band of heme complexes with $\mathrm{A} 1 \mathrm{M}$ as plotted at the wavelengths $422 \mathrm{~nm}\left(\lambda_{\max }\right.$ at low L/P) and $411 \mathrm{~nm}$ $\left(\lambda_{\max }\right.$ at higher L/P). observed spectral alterations included (a) a drastically red-shifted Soret band $(\sim 38 \mathrm{~nm}$ shifted in comparison with the spectrum of heme alone), (b) increasing intensity of this band, which remained stable when reaches maximum, and (c) characteristic isosbestic point for the spectra taken at different time-points (Figure 1B). These features are indicative of a complex formation between heme and A1M. Figure $1 \mathrm{C}$ shows UV/Vis absorption spectra of the A1M titration with heme which was performed by adding of small calculated aliquots of heme stock solution in DMSO to $45 \mu \mathrm{M}$ A1M in Tris buffer to increase the heme content in the heme/A1M mixture by 0.1 molar equivalent steps. As heme accomodation in A1M takes time (Figure 1B), each spectrum shown in Figure 1C was taken at a time point not less than 40 min after adding next heme aliquot to allow the reaction mixture to reach its equilibrium state, when no further significant alterations in the intensity or position of the Soret band were observed. Further titration resulted in a gradual increase of the Soret band intensity that was almost linearly proportional to the heme content in the sample (Figures 1C,D), and in the characteristic alteration of the Soret band $\lambda_{\max }$ from $422 \mathrm{~nm}$ (at low $\mathrm{L} / \mathrm{P}$ of 0.1 and 0.2 ) to $\lambda_{\max }$ at $411-412 \mathrm{~nm}$ observed for higher $\mathrm{L} / \mathrm{P}$.

As evident from the spectra obtained for the samples with heme content corresponding to low ligand-to-protein molar ratios $(\mathrm{L} / \mathrm{P})$ such as 0.1 and 0.2 , heme in $\mathrm{A} 1 \mathrm{M}$ solution exhibited a Soret band at $422 \mathrm{~nm}$ that is strongly red-shifted in comparison with heme in buffer alone (384 nm, Figure 1A). A bathochromic shift in UV/Vis absorption spectra provides evidence of a ligand complex formation with the host protein (Zsila et al., 2003, 2005; Neya et al., 2010). A large excess of the protein over heme promotes binding of heme primarily to the protein site(s) of high affinity, and a heme co-ordination by amino acid residues inside the primary binding site(s) may result in a higher energy level and thus, a red-shifted Soret band. Interestingly, the bathochromic shift observed for heme/A1M $(\sim 38 \mathrm{~nm})$ is much larger than those of plasma major heme scavengers hemopexin and human albumin which possess high affinities for heme and well-fit heme 
primary binding sites, and are characterized by Soret bands at 413 and $405 \mathrm{~nm}$, respectively.

A recent report (Siebel et al., 2012) suggested binding of two molecules of heme to each A1M molecule. This is supported by the results shown in Figure 1. Titration of A1M with heme (Figures 1C,D) suggested heme binding to a primary binding site of high affinity at low $\mathrm{L} / \mathrm{P}$ and also to a hypothetical secondary site of lower affinity at higher L/P. With increasing heme content, heme continued to fill both binding sites, and at higher $\mathrm{L} / \mathrm{P}$ values (starting L/P 0.6) the intensity of the Soret band at $411 \mathrm{~nm}$ prevailed over that at $422 \mathrm{~nm}$ (Figure 1D). At a heme-to-protein ratio higher than 1.2 (i.e., heme concentrations beyond $50 \mu \mathrm{M}$ ), some turbidity and slight precipitation could be observed. UV/Vis spectra of the supernatant showed a broad band around $405 \mathrm{~nm}$ with a shoulder at $355 \mathrm{~nm}$, very likely due to an overlapping of the Soret bands corresponding to aforementioned sites, free and aggregated heme in the solution, and non-specific heme binding at the protein surface, which, however, were beyond the scope of this study.

Thus, UV/Vis titration provided strong experimental evidence of the heme binding to A1M. The results were compatible with two heme binding sites as suggested previously (Siebel et al., 2012) and also raised the question of the nature of this extremely redshifted Soret band.

It is well known that heme can interact with His-tags (Asher and Bren, 2010) and can be involved in bis-His (hexa-) coordination (Owens et al., 2013). Therefore, the large bathochromic shift observed for heme/A1M samples (Figure 1) posed the question whether the His-tag may have an impact on the heme-binding. First, a native PAGE was run demonstrating that both Histagged A1M (tgA1M) and tagless A1M (ntA1M) indeed bind the heme molecule (Figure 2). Thus, the migration of both tgand nt-A1M was slowed by the heme bound (panel A), and the tryptophan-fluorescence completely quenched (panel B). A similar dose-response of migration shift and fluorescence quenching was noted for the two forms, suggesting similar affinities and coordination for tg- and nt-A1M. No effect on migration or fluorescence could be seen on the negative control ovalbumin by addition of heme.

To evaluate a possible involvement of the 8-mer His-tag in the hexa-coordination of heme iron, we first studied heme behavior in the mixtures with imidazole and L-His in comparison with heme in buffer alone (Figure 3A). In the L-His solutions in Tris buffer, heme exhibits a strong broad Soret band around $400 \mathrm{~nm}$ (Figure 3A) which is $\sim 16 \mathrm{~nm}$ red-shifted in comparison with heme in buffer alone. Even more remarkable, added to the imidazole solution in buffer, heme exhibits a strong Soret band at $436 \mathrm{~nm}$ with a shoulder at around $400 \mathrm{~nm}$ and two well-defined bands in the visible range, at 541 and $567 \mathrm{~nm}$ (Figure 3A). Both experiments suggest that imidazole side chains of the His-tagged protein may participate in the heme iron hexa-coordination by a sandwich structure when heme content is low in comparison with the protein (such as L/P 0.1 and 0.2 discussed above). However, when we examine His-octapeptide which was specifically synthesized to verify whether His-tag alone may provide heme hexa-coordination to cause a large bathochromic shift, such as $\sim 38 \mathrm{~nm}$, no significant difference was observed between the

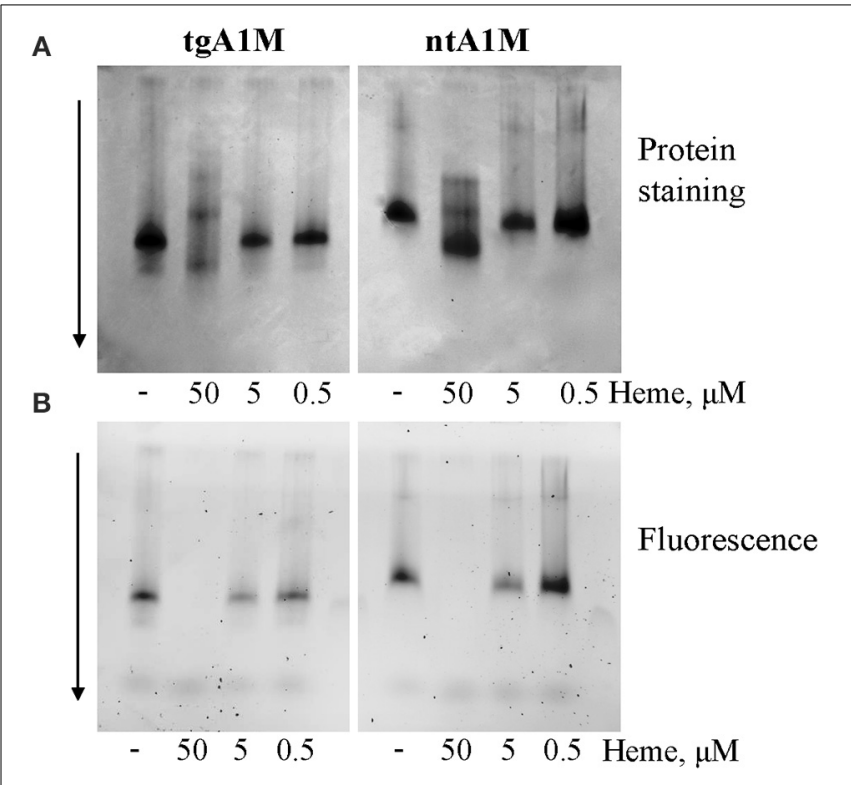

FIGURE 2 | Native gel data for heme/A1M samples. $\operatorname{tg} A 1 \mathrm{M}$ and $\mathrm{ntA} 1 \mathrm{M}$ $(5 \mu \mathrm{M})$ were incubated with 50,5 , and 0.5 and $0 \mu \mathrm{M}$ heme for $15 \mathrm{~min}$ at room temperature, and separated by electrophoresis in a $12 \%$ Criterion $^{\mathrm{TM}}$ TGXTM Precast stainfree Gels under non-denaturing and non-reducing conditions. The gels were either stained with Coommassie Brilliant Blue (A) or imaged by tryptophan fluorescence with a digital BioRad imager (B).

spectra of heme in His8-peptide solution and heme in buffer solution alone (Figure 3B). The $\lambda_{\max }(384 \mathrm{~nm})$ of the absorption band of heme/His8 sample (Figure 3B) was very much similar to that of heme in buffer alone (Figure 3A) as well as the decrease of its intensity in time (broken trace corresponding to $20 \mathrm{~h}$ in Figure $3 \mathrm{~B}$ ). Thus, contrary to imidazole and histidine, no sign of a complex formation with heme was observed for synthetic His-octapeptide under experimental conditions used.

This subject was further investigated with tagless A1M. Figure 4A shows differential UV/Vis titration spectra of ntA1M conducted the same way as that shown in Figure 1C. UV/Vis spectrum of the heme/ntA1M mixture of L/P 0.1 was characterized by a broad Soret band around $392 \mathrm{~nm}$, which is only $8 \mathrm{~nm}$ redshifted in comparison with that of heme in buffer alone $(384 \mathrm{~nm})$. $\mathrm{UV} / \mathrm{Vis}$ spectra corresponding to further titration of ntA1M with heme demonstrated similar trends to the Soret band blue shifting, however from 392 to $388 \mathrm{~nm}$ (Figures 4A,D), and an almost linear dependence between the intensity of the Soret band and heme content in the sample (not shown) as those observed for tgA1M. Comparison of the two titration sets demonstrates a difference between each pair of the tgA1M and ntA1M samples of the same $\mathrm{L} / \mathrm{P}$ at every step of the titration in terms of Soret band $\lambda_{\max }$ and shape of the spectra. As evident from the spectra overlays exemplified in Figure 4 for L/P 0.1 (panel B) and L/P 0.6 (panel C), $\mathrm{UV} / \mathrm{Vis}$ spectra of heme/tgA1M samples are significantly more narrow than those of heme/ntA1M, and the $\lambda_{\max }$ values of the corresponding Soret bands differ by $30 \mathrm{~nm}$ and $28 \mathrm{~nm}$, respectively. Figure $4 \mathrm{D}$ provides a summary of the $\lambda_{\max }$ values for the titration of tagged and tagless A1M variants over the entire heme 


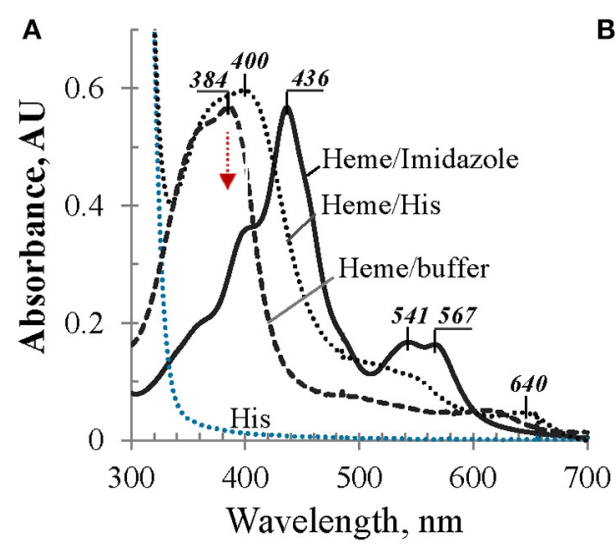

FIGURE 3 | UV/Vis spectral evaluation of possible bathochromic shift due to imidazole-containing compounds. (A) Absorbance spectra of heme in Tris buffer alone, in $0.1 \mathrm{M} \mathrm{L-His,} \mathrm{and} \mathrm{in} 0.1 \mathrm{M}$ imidazole

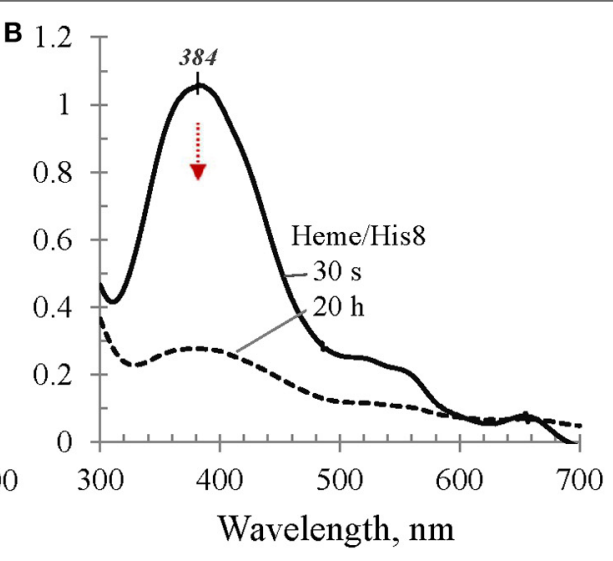

solutions, as labeled; (B) heme in $50 \mathrm{mM}$ solution of His8-peptide in Tris buffer: $30 \mathrm{~s}$ after adding heme aliquot and $20 \mathrm{~h}$ later, as marked; for details see Materials and Methods.

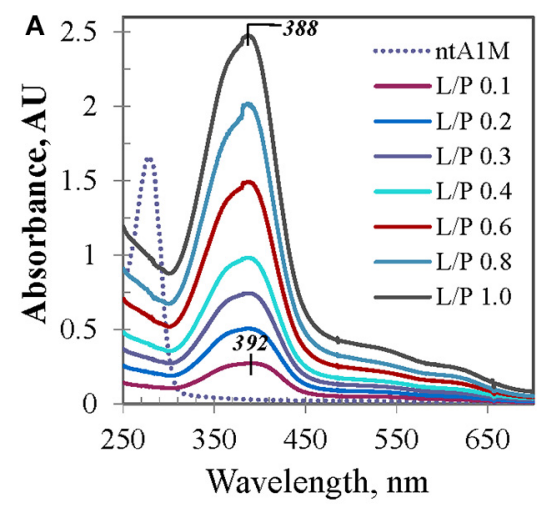

C

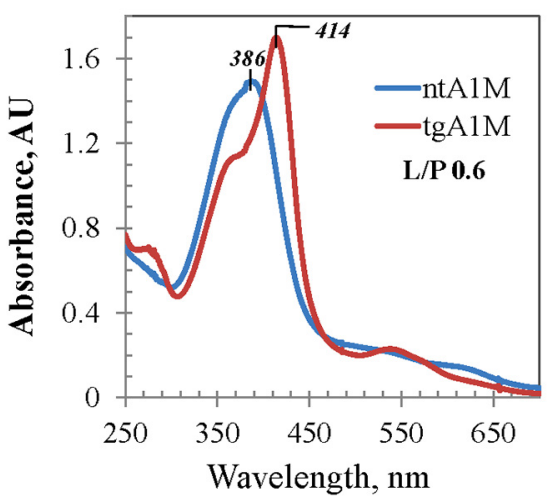

FIGURE 4 | UV/Vis absorbance data for ntA1M and comparison with tgA1M. (A) UVNis titration of ntA1M by heme (under conditions used for $\operatorname{tg} \mathrm{A} 1 \mathrm{M}$, Figure 1C); (B,C) UVNis spectra of heme complexes with tg- and

concentrations range used in this study. This plot implicates a His-tag involvement in the heme interactions with A1M, but also demonstrates a characteristic two-phase titration profile suggesting that heme binding to both $\operatorname{tg} \mathrm{A} 1 \mathrm{M}$ and ntA1M proceeds at two (primary and secondary) binding sites.

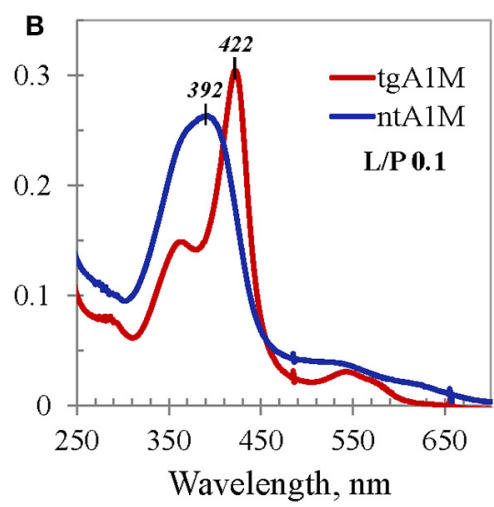

D

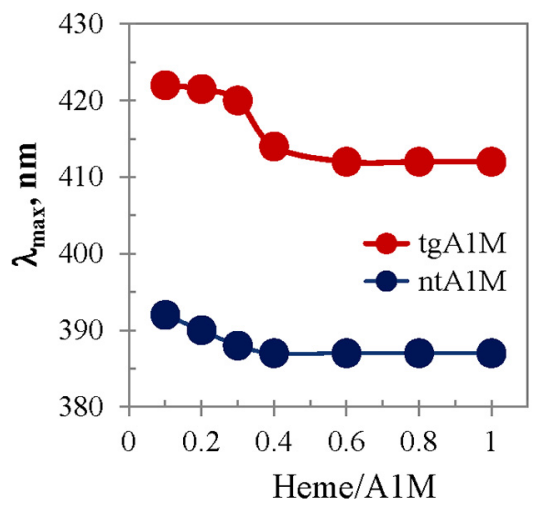

nt-A1M samples at low (L/P 0.1) and higher (L/P 0.6) heme-to-A1M molar ratio; (D) alterations of the Soret band $\lambda_{\max }$ of heme/tgA $1 \mathrm{M}$ and heme /ntA1M samples of the titration sets shown in Figures 1C, 3A.

\section{INDUCED CIRCULAR DICHROISM}

To provide more insight into the nature of the heme binding to $\mathrm{A} 1 \mathrm{M}$, we carried out a CD study in the visible range which may reflect heme induced optical activity due to its interaction with $\mathrm{A} 1 \mathrm{M}$, because otherwise heme per se is an optically inactive 
molecule. As demonstrated in Figure 5, neither heme nor A1M exhibited any $\mathrm{CD}$ in the visible range (dotted red and gray traces at zero-line, respectively). However, when the same amount of heme was added to the buffer solution containing A1M, a rapidly arising Cotton Effect (CE) was observed, a phenomenon known as protein-induced chirality (Zsila et al., 2004; Karnaukhova, 2007; Nagai et al., 2014). Further conformational changes (1 and $20 \mathrm{~h}$ traces are shown) were seen over time, with a slowly rising Soret CD band at $403 \mathrm{~nm}$ as the most prominent feature.

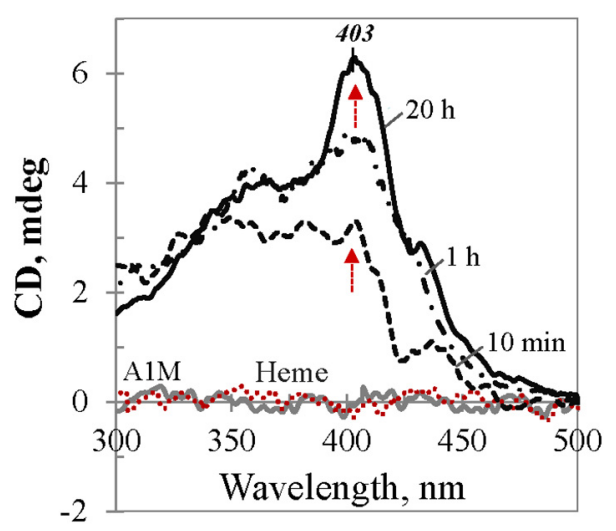

FIGURE 5 | CD dynamics of heme binding to tgA1M. The spectra correspond to $40 \mu \mathrm{M}$ heme in Tris buffer alone (red dotted trace at the baseline), and in $45 \mu \mathrm{M} \mathrm{A} 1 \mathrm{M}$ solution at the time points $10 \mathrm{~min}, 1 \mathrm{~h}$, and $20 \mathrm{~h}$, respectively (black traces). Gray spectrum corresponds to $45 \mu \mathrm{M}$ A1M in Tris buffer alone.
The induced CD spectra shown in Figure 5 for an equimolar mixture of heme and tgA1M, illustrate the dynamics of the complex formation. Contrary to UV/Vis absorption spectra, which reflect spectral properties of all heme species in the sample (free, bound to the protein internal binding site, or associated with protein at the surface), protein induced CD spectra, by definition, relate only to that part of heme which exhibits optical activity due to chiral perturbation to its structure per accomodation in the protein binding site. The CD spectra shown in Figure 5, in their original unsmoothed form, reflect ongoing conformational changes of the heme molecule. While at low heme content the binding to the A1M primary binding site proceeds relatively fast (with no further significant changes after $\sim 40 \mathrm{~min}$, not shown), heme binding to the secondary binding site proceeds slowly at higher heme-to-A1M ratio (Figure 5). It takes almost $20 \mathrm{~h}$ to achieve an equilibrium state with a well-defined positive $\mathrm{CE}$ at $403 \mathrm{~nm}$ and no further changes. The induced CE is in a good agreement with the $\lambda_{\max }$ of the Soret band in the complementary $\mathrm{UV} / \mathrm{Vis}$ spectrum (which is $\sim 411 \mathrm{~nm}$ for $\mathrm{L} / \mathrm{P} 1.0$ ).

Figure 6 shows induced CD spectra of the heme complexes with tgA1M (panel A) and ntA1M (B) at L/P 0.1 and 1.0, after an equilibrium was achieved by each mixture (the spectra were measured at $20 \mathrm{~h}$ after adding heme). According to Figure 5A, the induced CD of the heme/tgA1M sample with L/P 0.1 demonstrates a small positive $\mathrm{CE}$ at $421 \mathrm{~nm}$, thus reflecting the heme environment at the primary binding site. The CD spectrum corresponding to L/P 1.0 shows significantly different $\mathrm{CE}$ at $403 \mathrm{~nm}$, very likely due to binding of the heme molecule at the secondary binding site, whereas a shoulder around $420 \mathrm{~nm}$ still suggest an overlap of the induced CD spectra from both binding sites. The
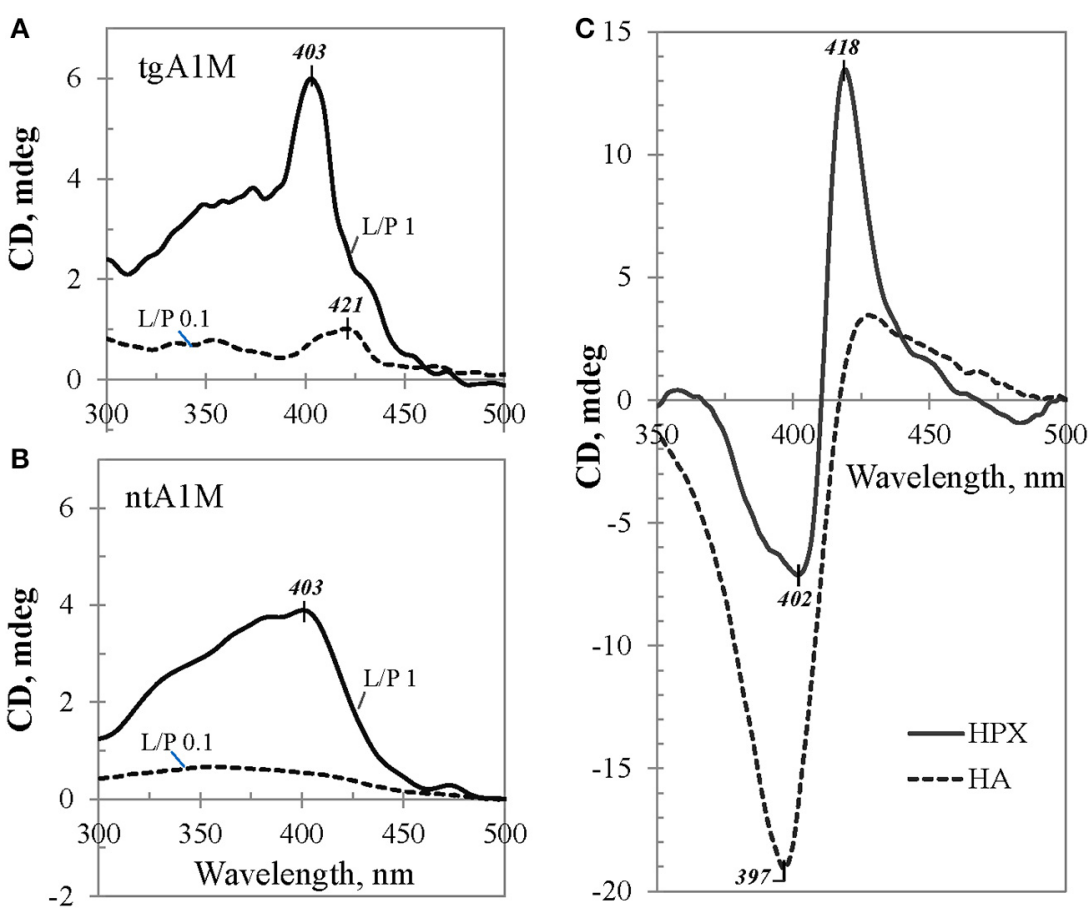

FIGURE 6 | Induced CD data. Selected visible CD spectra of heme complexes with (A) $\operatorname{tg} A 1 M$ and (B) ntA1M, shown for L/P 0.1 (broken trace) and L/P 1.0 (solid trace), and $\mathbf{( C )}$ reference proteins HA and HPX. All samples were of approximately the same initial protein concentration, $\sim 45 \mu \mathrm{M}$. 
induced CD spectra of heme/ntA1M samples (Figure 6B) are broader and of lower intensity of the induced CE. While CD spectrum corresponding to the sample with $\mathrm{L} / \mathrm{P} 0.1$ is weak, the induced CD spectrum of heme/ntA1M of L/P 1.0 shows CE at the same $403 \mathrm{~nm}$ as that observed for heme/tgA1M (panel A), although of lower intensity. Comparison of the induced CD data visualizes the impact of His-tag, but also indicates that ntA1M binds at least one of the heme-groups at the same binding site as the tagged A1M does, as evident from their CE at $403 \mathrm{~nm}$.

The induced CE observed for heme/A1M samples were compared with those measured for heme/HPX and heme/HA samples of the same heme-to-protein molar ratio (Figure 6C). Although the three proteins are quite different, the intensity of the induced $\mathrm{CD}$ is generally determined by the strength of heme interactions with each protein and geometry of the binding site (Daviter et al., 2013). Therefore, higher intensities of the induced CD spectra in case of heme/HPX and heme/HA, in comparison with that of heme/A1M, suggest that heme binding sites in hemopexin and albumin are tighter and of higher affinity than those of A1M. Furthermore, while the CD titration spectra of heme/HPX and heme/HA at L/P 0.1 and up to 1.0 are indicative of one main heme binding site, the differences between heme/A1M CD spectra at low L/P and higher L/P support heme binding at two binding sites.

\section{SPR KINETICS OF HEME BINDING TO A1M}

SPR (Biacore) was used to study the real-time kinetics of the heme interactions with $\mathrm{A} 1 \mathrm{M}$ using different approaches. Our attempts to immobilize A1M directly on the CM5 surface were unsuccessful. Instead, we immobilized A1M by using the Histag of the recombinant protein as an anchor for immobilization (Kimple et al., 2010). This approach also has the advantages of reducing the possible impact of the His-tag on coordination with heme, and allowing studies of other possible ligands besides heme. Therefore, we first explored immobilization of tgA1M by the His-tag using NTA chip as described elsewhere (Khan et al., 2006; Fischer et al., 2011). However, although tgA1M was successfully immobilized on the NTA sensor chip, we experienced continuous dissociation of the immobilized A1M from the surface, which was also reported for some other proteins (Willard and Siderovski, 2006; Clow et al., 2008). Instead, we used primary immobilization of anti-His mouse IgG1 monoclonal antibody (Franco et al., 2013). With this approach we were able to successfully capture the $\operatorname{tgA} 1 \mathrm{M}$ to a highly pure homogeneous surface used for heme binding kinetics over a wide range of heme concentrations from $500 \mu \mathrm{M}$ down to $0.625 \mu \mathrm{M}$. Interestingly, with a heme concentration range of $0.625-100 \mu \mathrm{M}$ (Figure 7), the SPR data were a perfect fit to 1:1 Langmuir binding model, yielding kinetic rate constants $\mathrm{k}_{\mathrm{a}}$ and $\mathrm{k}_{\mathrm{d}}$ of $561.1 \mathrm{M}^{-1} \mathrm{~s}^{-1}$ and $7.75 \times$ $10^{-3} \mathrm{~s}^{-1}$, respectively, and resulting in an equilibrium binding constant $\mathrm{K}_{\mathrm{D}}$ of $13.82 \mu \mathrm{M}$. When the heme concentration range was extended to higher concentrations (up to $500 \mu \mathrm{M}$ ), the experimental data fitted better to a 1:2 binding model, thus supporting two binding site model suggested by Siebel and co-workers (Siebel et al., 2012). Using this model, the stronger affinity binding site was characterized by the association $\left(\mathrm{k}_{\mathrm{a}}\right)$ and dissociation $\left(\mathrm{k}_{\mathrm{d}}\right)$ rates $405.4 \mathrm{M}^{-1} \mathrm{~s}^{-1}$ and $2.85 \times 10^{-3} \mathrm{~s}^{-1}$, respectively, thus resulting in a calculated $K_{D}$ value of $7.02 \mu \mathrm{M}$. The binding site of lower affinity was characterized by $k_{a}$ of $110.8 \mathrm{M}^{-1} \mathrm{~s}^{-1}$ and $\mathrm{k}_{\mathrm{d}}$ of $0.02106 \mathrm{~s}^{-1}$, yielding a calculated $\mathrm{K}_{\mathrm{D}}$ value of $190 \mu \mathrm{M}$. However, the accuracy of the $\mathrm{K}_{\mathrm{D}}$ evaluation for the low affinity binding site can very likely be impacted by a heme tendency to aggregate at higher concentrations.

For the primary binding site, the SPR results reproducibly showed $\mathrm{K}_{\mathrm{D}}$ values in the low micromolar range (as shown above, 13.82 and $7.02 \mu \mathrm{M}$ ) which is consistent with that determined earlier by a different technique (Larsson et al., 2004). It is noteworthy that at neutral buffer, such as $\mathrm{pH} 7.2$ (data not shown) heme affinity to $\mathrm{A} 1 \mathrm{M}$ was $\sim 10$-fold weaker than at $\mathrm{pH} 8$, very likely due to a better heme solubility at more basic conditions. This observation seems to be in agreement with our CD data as a stronger intensity of the induced $\mathrm{CD}$ was observed for heme/A1M samples at $\mathrm{pH} 8$ than at $\mathrm{pH} 7.2-7.4$ (not shown).

\section{CATALASE-LIKE ACTIVITY ASSESSMENT}

The heme/tgA1M and heme/ntA1M samples were assessed for catalase-like activity in order to evaluate the accessibility of heme in these complexes to hydrogen peroxide in comparison to that of free heme in buffer. As shown in Figure 8A, when an aliquot of hydrogen peroxide is added to a freshly prepared heme solution in
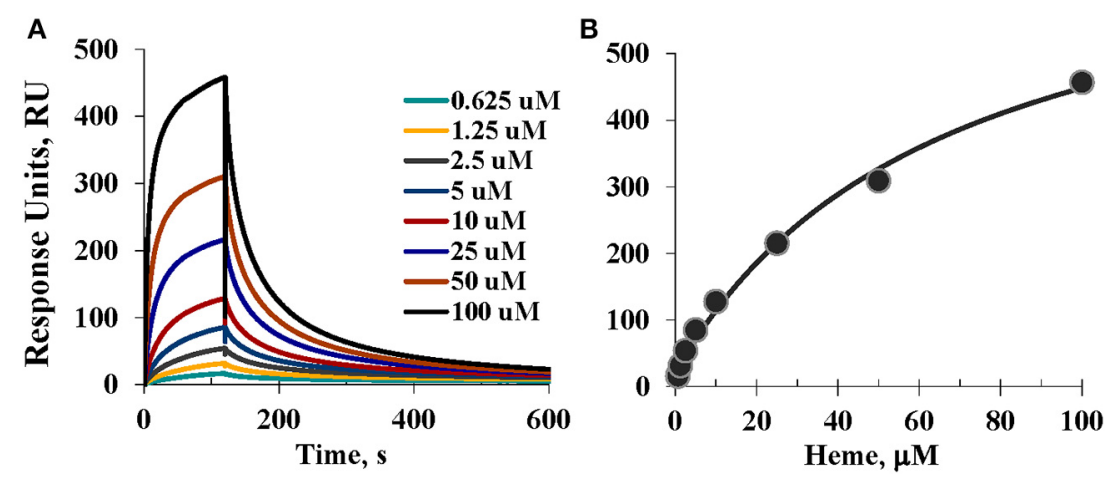

FIGURE 7 | SPR assessment. (A) Sensorgrams of the heme binding to A1M captured by the anti-His mouse IgG1 monoclonal antibody immobilized on CM5 sensor chip; and (B) Steady-state equilibrium analysis and fitting; see details in Materials and Methods. 

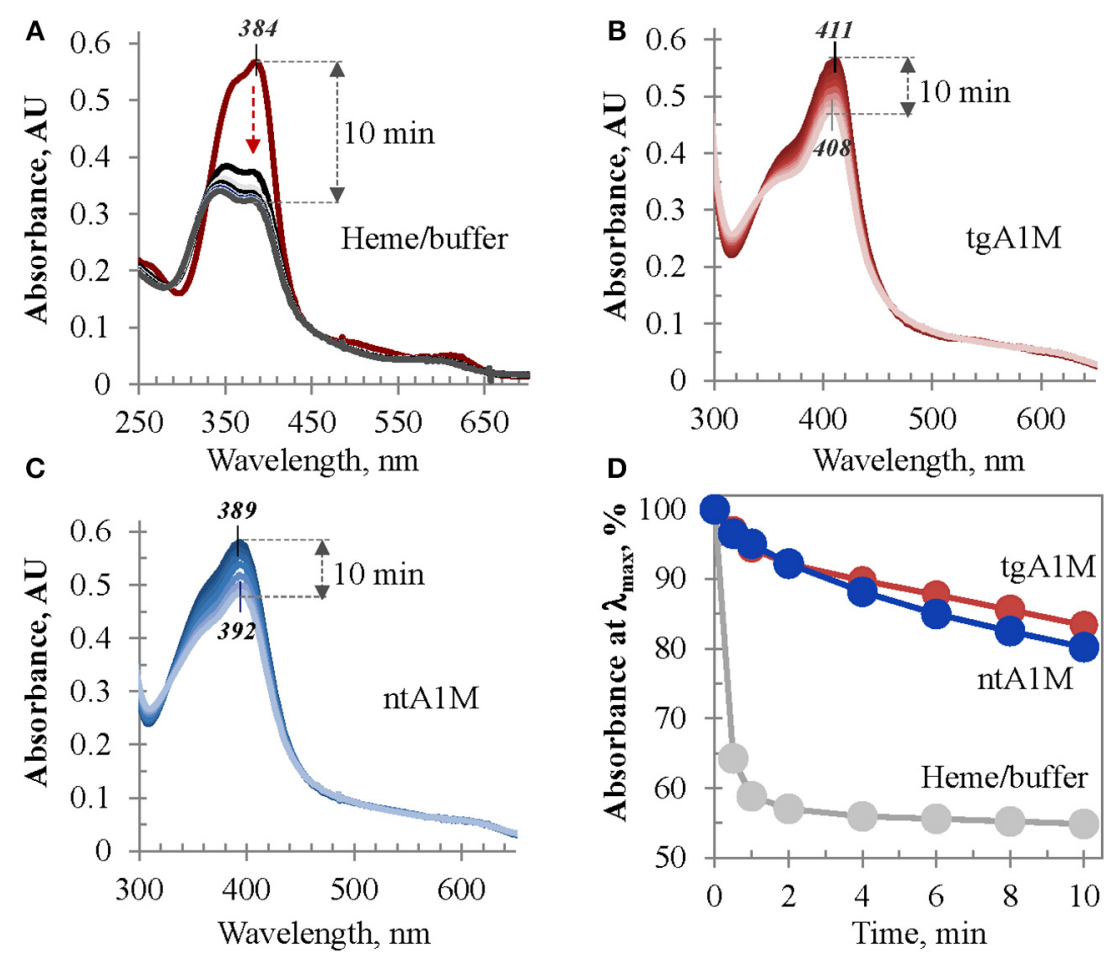

FIGURE 8 | Heme catalase-like activity. (A-C) UVNis monitoring of the Soret band intensity of heme samples in Tris buffer alone (A), and in complexes with $\operatorname{tg} \mathrm{A} 1 \mathrm{M}$ (B) and $\mathrm{ntA} 1 \mathrm{M}$ (C); (D) alterations of the Soret band initial intensity (\%) measured over 10 min after addition of hydrogen

peroxide. Heme complexes with $\operatorname{tg} \mathrm{A} 1 \mathrm{M}$ and $\mathrm{ntA} 1 \mathrm{M}$ were prepared $20 \mathrm{~h}$ prior to these measurements, whereas heme/buffer sample of the same absorbance intensity was freshly prepared; for more details see Materials and Methods.

Tris buffer, the intensity of its Soret band drastically drops within first $30 \mathrm{~s}$, and $2 \mathrm{~min}$ later more than $42 \%$ of the initial intensity is lost. However, when the same amount of hydrogen peroxide is added to heme/tgAlM and heme/ntA1M solutions in Tris buffer, a very limited decrease of the Soret band intensity is observed for both samples (Figures $\mathbf{8 B}, \mathbf{C}$ ). Figure $\mathbf{8 D}$ provides a comparative summary for this functional assessment, suggesting that heme accessibility in the complexes with tgA1M and ntA1M is almost the same, and both A1M variants shield ferriheme from oxidation and partial decomposition by peroxide in a comparable fashion.

\section{BIOLOGICAL IMPLICATIONS}

Free heme exerts toxic effects in biological tissues mainly through oxidative reactions of the iron (Kumar and Bandyopadhyay, 2005). Heme causes tissue injury by catalyzing oxidation of proteins, lipids and DNA. Since the heme group is a lipophilic molecule it intercalates lipid bilayer membranes and destabilizes plasma membranes, mitochondria and nucleus. The primary targets of free heme in blood are the endothelial cells and kidneys. Thus, in vivo pro-inflammatory effects and renal toxicity have been reported in animals (Wagener et al., 2001; Rodriguez et al., 2003). The free heme toxicity in blood is probably mitigated to a large part by albumin and hemopexin, but A1M has recently been suggested among the innate defense molecules as having a role primarily in the extravascular compartments (Akerström and Gram, 2014). Besides the heme-binding, A1M also yields antioxidative protection by radical-scavenging and

reductase activity. Together, these three mechanisms gives the protein a powerful therapeutic potential and it was indeed shown that recombinant His-tagged A1M could be employed for in vivo treatment of the pregnancy disease preeclampsia, characterized by hypertension and kidney dysfunction, in a sheep model (WesterRosenlöf et al., 2014) and Hb-induced glomerular dysfunction in rats (Sverrisson et al., 2014).

\section{CONCLUSIONS}

We have investigated heme interactions with recombinant A1M using UV/Vis absorption spectrometry, visible CD, SPR, migration-shift PAGE, and catalase-like activity assay. The latter four methods have not previously been applied for this purpose and provide a deeper insight into the dynamics and character of heme interactions with A1M. The results support the previously suggested two binding site model with binding affinities in the micromolar range. For the first time, induced visible $\mathrm{CD}$ visualizes the differences in the heme microenvironment at the AlM high and low affinity binding sites. The results also show that His-tagged and tagless A1M bind heme in a similar fashion, although the His-tag seems to be involved in the coordination with heme iron. This study thus provides an analytical platform for rapid evaluation of the ligand-binding properties of recombinant $\mathrm{A} 1 \mathrm{M}$ versions including induced visible $\mathrm{CD}$ and an efficient SPR approach based on the capturing of tagged A1M by using anti-His-tag antibody, which also may be suitable for other recombinant proteins. 


\section{ACKNOWLEDGMENTS}

This work was supported in part by the National Institutes of Health (NIH) under grants HL110900 (Abdu I. Alayash), and U.S. Food and Drug Administration (MODSCI 2013), and by governmental ALF research grants to Lund University and Lund University Hospital, the Royal Physiographic Society in Lund, the Foundations of Greta and Johan Kock, Alfred Österlund, the Blood and Defence Network, Lund University, and the Crafoord Foundation (20081029). Mohsen Rajabi is grateful to the Oak Ridge Institute for Science and Education (ORISE) for fellowship.

\section{REFERENCES}

Åkerström, B., Flower, D. R., and Salier, J. P. (2000). Lipocalins: unity in diversity, Biochim. Biophys. Acta 1482, 1-8. doi: 10.1016/S0167-4838(00) 00137-0

Åkerström, B., and Gram, M. (2014). A1M, an extravascular tissue cleaning and housekeeping protein. Free Radic. Biol. Med. 74C, 274-282. doi: 10.1016/j.freeradbiomed.2014.06.025

Åkerström, B., Maghzal, G. J., Winterbourn, C. C., and Kettle, A. J. (2007). The lipocalin $\alpha_{1}$-microglobulin has radical scavenging activity. J. Biol. Chem. 282, 31493-31503. doi: 10.1074/jbc.M702624200

Alayash, A. I. (2014). Blood substitutes: why haven't we been more successful? Trends Biotechol. 32, 177-185. doi: 10.1016/j.tibtech.2014.02.006

Allhorn, M., Berggard, T., Nordberg, J., Olsson, M. L., and Åkerström, B. (2002). Processing of the lipocalin $\alpha_{1}$-microglobulin by hemoglobin induces heme-binding and heme-degradation properties. Blood 99, 1894-1901. doi: 10.1182/blood.V99.6.1894

Allhorn, M., Klapyta, A., and Åkerström, B. (2005). Redox properties of the lipocalin $\alpha_{1}$-microglobulin: reduction of cytochrome $c$, hemoglobin, and free iron. Free. Radic. Biol. Med. 38, 557-567. doi: 10.1016/j.freeradbiomed.2004. 12.013

Ascenzi, P., Bocedi, A., Visca, P., Altruda, F., Tolosano, E., Beringhelli, T., et al. (2005). Hemoglobin and heme scavenging. IUBMB Life 57, 749-759. doi: 10.1080/15216540500380871

Asher, W. B., and Bren, K. L. (2010). A heme fusion tag for protein affinity purification and quantification. Protein Sci. 19, 1830-1839. doi: 10.1002/pro.460

Belcher, J. D., Chen, C., Nguyen, J., Milbauer, L., Abdulla, F., Alayash, A. I., et al. (2014). Heme triggers TLR4 signaling leading to endothelial cell activation and vaso-occlusion in murine sickle cell disease. Blood 123, 377-390. doi: 10.1182/blood-2013-04-495887

Breustedt, D. A., Schönfeld, D. L., and Skerra, A. (2006). Comparative ligandbinding analysis of ten human lipocalins. Biochim. Biophys. Acta 1764, 161-173. doi: 10.1016/j.bbapap.2005.12.006

Buehler, P. W., Karnaukhova, K., Gelderman, M. P., and Alayash, A. I. (2011). Blood aging, safety and transfusion: capturing the "radical" menace. Antiox. Redox Signal. 14, 1713-1728. doi: 10.1089/ars.2010.3447

Clow, F., Fraser, J. D., and Proft, T. (2008). Immobilization of proteins to biacore sensorchips using Staphylococcus aureus sortase A. Biotechnol. Lett. 30, 1603-1607. doi: 10.1007/s10529-008-9718-1

Collier, G. S., Pratt, J. M., de Wet, C. R., and Tshabalala, C. F. (1979). Studies on haemin in dimethyl sulphoxide/water mixtures. Biochem. J. 179, 281-289.

Daviter, T., Chmel, N., and Rodger, A. (2013). Circular and linear dichroism spectroscopy for the study of protein-ligand interactions. Methods Mol. Biol. 1008, 211-241. doi: 10.1007/978-1-62703-398-5_8

Dutra, F. F., and Bozza, M. T. (2014). Heme on innate immunity and inflammation. Front. Pharmacol. 5:115. doi: 10.3389/fphar.2014.00115

Eskew, J. D., Vanacore, R. M., Sung, L. M., Morales, P. J., and Smith, A. (1999). Cellular protection mechanisms against extracellular heme. J. Biol. Chem. 274, 638-648. doi: 10.1074/jbc.274.2.638

Fischer, M., Leech, A. P., and Hubbard, R. E. (2011). Comparative assessment of different histidine-tags for immobilization of protein onto surface plasmon resonance sensorchips. Anal. Chem. 83, 1800-1807. doi: 10.1021/ac103168q

Flower, D. R. (2000). Experimentally determined lipocalin structures. Biochim. Biophys. Acta 1482, 46-56. doi: 10.1016/S0167-4838(00)00147-3

Franco, A., Damdinsuren, B., Ise, T., Dement-Brown, J., Li, H., Nagata, S., et al. (2013). Human Fc receptor-like 5 binds intact IgG via mechanisms distinct from those of Fc receptors. J. Immunol. 190, 5739-5746. doi: 10.4049/jimmunol.1202860

Ganfornina, M. D., Sanchez, D., Greene, L. H., and Flower, D. (2006). "The lipocalin protein family: protein sequence, structure and relationship to the calycin superfamily," in Lipocalins, eds B. Åkerström, N. Borregaard, D. R. Flower, and J.-P. Salier (Georgetown, TX: Landes Bioscience), 17-27.

Gill, S. C., and von Hippel, P. H. (1989). Calculation of protein extinction coefficients from amino acid sequence data. Anal. Biochem. 182, 319-326. doi: 10.1016/0003-2697(89)90602-7

Jeney, V., Balla, J., Yachie, A., Varga, Z., Vercellotti, G. M., Eaton, J. W., et al. (2002). Pro-oxidant and cytotoxic effects of circulating heme. Blood 100, 879-887. doi: 10.1182/blood.V100.3.879

Karnaukhova, E. (2007). Interactions of human serum albumin with retinoic acid, retinal and retinyl acetate. Biochem. Pharmacol. 73, 901-910. doi: 10.1016/j.bcp.2006.11.023

Karnaukhova, E., Krupnikova, S. S., Rajabi, M., and Alayash, A. I. (2012). Heme binding to alpha-1 proteinase inhibitor. Biochim. Biophys. Acta 1820, 2020-2029. doi: 10.1016/j.bbagen.2012.09.012

Khan, F., He, M., and Taussig, M. G. (2006). Double-hexahistidine tag with high-affinity binding for protein immobilization, purification, and detection on Ni-nitrilo-triacetic acid surfaces. Anal. Chem. 78, 3072-3079. doi: 10.1021/ac0601841

Kimple, A. J., Muller, R. E., Siderovski, D. P., and Willard, F. S. (2010). A capture coupling method for the covalent immobilization of hexahistidine tagged proteins for surface plasmon resonance. Methods Mol. Biol. 627, 91-100. doi: 10.1007/978-1-60761-670-2_5

Kumar, S., and Bandyopadhyay, U. (2005). Free heme toxicity and its detoxification systems in human. Toxicol. Lett. 157, 175-188. doi: 10.1016/j.toxlet.2005.03.004

Kwasek, A., Osmark, P., Allhorn, M., Lindqvist, A., Åkerström, B., and Wasylewski, Z. (2007). Production of recombinant human $\alpha_{1}$-microglobulin and mutant forms involved in chromophore formation. Protein Expr. Purif. 53, 145-152. doi: 10.1016/j.pep.2006.10.023

Larsson, J., Allhorn, M., and Åkerström, B. (2004). The lipocalin $\alpha_{1}$-microglobulin binds heme in different species. Arch. Biochem. Biophys. 432, 196-204. doi: 10.1016/j.abb.2004.09.021

Nagai, M., Nagai, Y., Imai, K., and Neya, S. (2014). Circular dichroism of hemoglobin and myoglobin. Chirality 26, 438-442. doi: 10.1002/chir.22273

Neya, S., Suzuki, M., Hoshino, T., Ode, H., Imai, K., Komatsu, T., et al. (2010). Molecular insight into intrinsic heme distortion in ligand binding in hemoproteins. Biochemistry 49, 5642-5650. doi: 10.1021/bi1003553

Olsson, M. G., Allhorn, M., Bulow, L., Hansson, S. R., Ley, D., Olsson, M. L., et al. (2012). Pathological conditions involving extracellular hemoglobin: molecular mechanisms, clinical significance, and novel therapeutic opportunities for $\alpha_{1}$ microglobulin. Antiox. Redox Signal. 17, 813-846. doi: 10.1089/ars.2011.4282

Olsson, M. G., Olofsson, T., Tapper, H., and Åkerström, B. (2008). The lipocalin $\alpha_{1}$ microglobulin protects erythroid $\mathrm{K} 562$ cells against oxidative damage induced by heme and reactive oxygen species. Free Radic. Res. 42, 725-736. doi: 10.1080/10715760802337265

Owens, C. P., Du, J., Dawson, J. H., and Goulding, C. W. (2013). Characterization of heme ligation properties of Rv0203, a secreted heme binding protein involved in Mycobacterium tuberculosis heme uptake. Biochemistry 51, 1518-1531. doi: 10.1021/bi2018305

Rodriguez, F., Kemp, R., Balazy, M., and Nasjletti, A. (2003). Effects on exogenous heme on renal function: role of heme oxygenase and cyclooxygenase. Hypertension 42, 680-684. doi: 10.1161/01.HYP.0000085785.40581.1A

Rutardottir, S., Nilsson, E. J. C., Pallon, J., Gram, M., and Åkerström, B. (2013). The cysteine 34 residue of $\mathrm{A} 1 \mathrm{M} / \alpha_{1}$-microglobulin is essential for protection of irradiated cell cultures and reduction of carbonyl groups. Free Radic. Res. 47, 541-550. doi: 10.3109/10715762.2013.801555

Siebel, J. F., Kosinsky, R. L., Åkerström, B., and Knipp, M. (2012). Insertion of heme $b$ into the structure of the Cys34-carbamidomethylated human lipocalin $\alpha_{1}$-microglobulin: formation of a $\left[(\text { heme })_{2}\left(\alpha_{1} \text {-microglobulin }\right)\right]_{3}$ complex. Chembiochem 13, 879-887. doi: 10.1002/cbic.201100808

Siegert, S. W. K., and Holt, R. J. (2008). Physicochemical properties, pharmacokinetics, and pharmacodynamics of intravenous hematin: a literature review. $A d v$. Ther. 25, 842-857. doi: 10.1007/s12325-008-0094-y

Smith, L. J., Kahraman, A., and Thornton, J. M. (2010). Heme proteins-diversity in structural characteristics, function, and folding. Proteins 78, 2349-2368. doi: $10.1002 /$ prot. 22747 
Sverrisson, K., Axelsson, J., Rippe, A., Gram, M., Åkerström, B., Hansson, S. R., et al. (2014). Extracellular fetal hemoglobin induces increases in glomerular permeability: inhibition with $\alpha_{1}$-microglobulin and tempol. Am. J. Physiol. Renal Physiol. 306, F442-F448. doi: 10.1152/ajprenal. 00502.2013

Tenhunen, R., and Mustajoki, P. (1998). Acute porphyria: treatment with heme. Semin. Liver Dis. 18, 53-55. doi: 10.1055/s-2007-1007140

Vinchi, F., De Franceschi, L., Ghigo, A., Townes, T., Cimino, J., Silengo, L., et al. (2013). Hemopexin therapy improves cardiovascular function by preventing heme-induced endothelial toxicity in mouse models of hemolytic diseases. Circulation 127, 1317-1329. doi: 10.1161/CIRCULATIONAHA.112. 130179

Wagener, F. A. D. T. G., Eggert, A., Boerman, O. C., Oyen, W. J. G., Verhofstad, A., Abraham, N. G., et al. (2001). Heme is a potent inducer of inflammation in mice and is counteracted by heme oxygenase. Blood 98, 1802-1811. doi: 10.1182/blood.V98.6.1802

Wester-Rosenlöf, L., Casslén, V., Axelsson, J., Edström-Hägerwall, A., Gram, M., Holmqvist, M., et al. (2014). A1M $/ \alpha_{1}-$ microglobulin protects from heme-induced placental and renal damage in a pregnant sheep model of preeclampsia. PLoS ONE 9:e86353. doi: 10.1371/journal.pone.00 86353

Willard, F. S., and Siderovski, D. P. (2006). Covalent immobilization of histidinetagged proteins for surface plasmon resonance. Anal. Biochem. 353, 147-149. doi: 10.1016/j.ab.2006.02.004

Zsila, F., Bikádi, Z., Fitos, I., and Simonyi, M. (2004). Probing protein binding sites by circular dichroism spectroscopy. Curr. Drug Discov. Technol. 1, 133-153. doi: $10.2174 / 1570163043335135$
Zsila, F., Bikádi, Z., and Simonyi, M. (2003). Probing the binding of the flavonoid, quercetin to human serum albumin by circular dichroism, electronic absorption spectroscopy and molecular modelling methods. Biochem. Pharmacol. 65, 447-456. doi: 10.1016/S0006-2952(02)01521-6

Zsila, F., Molnár, P., Deli, J., and Lockwood, S. F. (2005). Circular dichroism and absorption spectroscopic data reveal binding of the natural cis-carotenoid bixin to human $\alpha_{1}$-acid glycoprotein. Bioorg. Chem. 33, 298-309. doi: 10.1016/j.bioorg.2005.03.003

Conflict of Interest Statement: The authors declare that the research was conducted in the absence of any commercial or financial relationships that could be construed as a potential conflict of interest.

Received: 24 September 2014; accepted: 13 November 2014; published online: 04 December 2014.

Citation: Karnaukhova E, Rutardottir S, Rajabi M, Wester Rosenlöf L, Alayash AI and Akerström B (2014) Characterization of heme binding to recombinant $\alpha_{1}$ microglobulin. Front. Physiol. 5:465. doi: 10.3389/fphys.2014.00465

This article was submitted to Oxidant Physiology, a section of the journal Frontiers in Physiology.

Copyright (c) 2014 Karnaukhova, Rutardottir, Rajabi, Wester Rosenlöf, Alayash and Akerström. This is an open-access article distributed under the terms of the Creative Commons Attribution License (CC BY). The use, distribution or reproduction in other forums is permitted, provided the original author(s) or licensor are credited and that the original publication in this journal is cited, in accordance with accepted academic practice. No use, distribution or reproduction is permitted which does not comply with these terms. 